\title{
Pênfigo foliáceo em eqüino: relato de caso
}

[Equine pemphigus foliaceous: case report]

\author{
J.P. Oliveira Filho', R.C. Gonçalves ${ }^{1}$, S.B. Chiacchio', R.M. Amorim ${ }^{1}$, L.G. Conceição ${ }^{2}$, A.S. Borges * \\ ${ }^{1}$ Faculdade de Medicina Veterinária e Zootecnia - UNESP \\ Distrito de Rubião Junior, $\mathrm{s} / \mathrm{n}$ \\ 18618-000 - Botucatu, SP \\ ${ }^{2}$ Departamento de Veterinária - UFV - Viçosa, MG
}

\begin{abstract}
RESUMO
Diagnosticou-se pênfigo foliáceo em um eqüino macho, castrado, quatro anos de idade da raça Árabe apresentando dermatite generalizada caracterizada por placas escamo-crostosas e presença de dermatite pustular acantolítica subcorneal.
\end{abstract}

Palavras-chave: eqüino, pênfigo foliáceo, dermatite

\begin{abstract}
Pemphigus foliaceus was diagnosed in a four-year-old Arabian equine gelding, with generalized dermatitis characterized by scaling and crusting plaques and acantholytic subcorneal pustular dermatitis.
\end{abstract}

Keywords: equine, pemphigus foliaceus, dermatitis

\section{INTRODUÇ̃̃O}

Pênfigo é uma doença auto-imune descrita em humanos e em várias espécies de animais domésticos (Stannard, 2000; Pappalardo et al., 2002; Vandenabeele et al., 2004). Em humanos existem cerca de oito variedades de pênfigo, contudo em cavalos só foram descritas três variedades: pênfigo foliáceo, pênfigo paraneoplásico e pênfigo vulgar (Williams et al., 1995; Scott e Miller, 2003). As duas últimas são raras em eqüinos, enquanto que a primeira é a dermatopatia auto-imune mais comum em cavalos nos Estados Unidos, corresponde a 1,89\% dos casos de doenças cutâneas, atendidas na Universidade de Cornell (Scott e Miller, 2003). Existem descrições dessa enfermidade em cavalos nos Estados Unidos, Europa e Austrália (Laing et al., 1992; Vandenabeele et al., 2004; Stahli et al., 2005; Zabel et al., 2005).

Recebido em 10 de fevereiro de 2006

Aceito em 20 de setembro de 2007

* Autor para correspondência (corresponding author)

E-mail: asborges@fmvz.unesp.br
$O$ pênfigo foliáceo $(\mathrm{PF})$ em eqüinos caracterizase clinicamente por lesões erosadas ou crostosas, anulares com ou sem a presença de "colarinho" epidérmico, alopecia e variado grau de exsudação e descamação (Scott e Miller, 2003; Vandenabeele et al., 2004; Zabel et al., 2005). Edema abdominal ventral, dor e prurido podem estar presentes (Scott e Miller, 2003; Zabel et al., 2005). Manifestações sistêmicas como depressão, letargia, hiporexia, perda de peso e febre estão presentes em 50\% dos casos descritos (Scott e Miller, 2003; Vandenabeele et al., 2004).

Eqüinos com PF apresentam anticorpos contra as moléculas de adesão na superfície dos ceratinócitos, levando à perda da coesão intracelular e acantólise (Pfeiffer et al., 1988; Stannard, 2000). Ceratinócitos acantolíticos podem ser observados nos exames citológico e histológico das lesões pustulares ou crostosas (Messer e Knight, 1982; Mullowney, 1985; Vandenabeele et al., 2004; Zabel et al., 2005). 
O diagnóstico de PF é obtido por meio da história clínica, achados clínicos e histológicos. A identificação dos anticorpos por imunofluorescência direta pode colaborar com o diagnóstico (Rothwell et al., 1985; Scott e Miller, 2003; Stahli et al., 2005), mas não é recomendado o uso da imunofluorescência indireta para o diagnóstico de $\mathrm{PF}$ em eqüino (Scott et al., 1984).

Johnson et al. (1981) descreveram o primeiro caso de PF em cavalos, nos Estados Unidos da América. Estudos retrospectivos foram publicados em 1987 (Scott et al., 1987), 2004 (Vandenabeele et al., 2004) e em 2005 (Zabel et al., 2005), contudo existem ainda poucas descrições da doença no mundo (Vandenabeele et al., 2004). Este artigo tem como objetivo descrever o primeiro caso de PF em eqüino no Brasil, já que não há relatos na literatura nacional consultada.

\section{RELATO DO CASO}

Um eqüino macho, castrado, da raça Árabe, com quatro anos de idade, foi encaminhado para atendimento clínico por apresentar lesões cutâneas distribuídas por todo o corpo, edema na região ventral, apatia e perda de aproximadamente $100 \mathrm{~kg}$ de peso vivo (pv). O proprietário relatou que esses sinais clínicos apareceram há 30 dias na região da face e que a terapia com antibióticos sistêmicos e antifúngicos tópicos não resultou em melhora clínica. Nesse período houve piora progressiva das manifestações, com disseminação das lesões por todo o corpo.

Ao exame físico o eqüino mostrava-se apático, anoréxico e relutante em se locomover, apresentava edema na região ventral do abdômen e nos quatro membros. As freqüências cardíaca e respiratória e a temperatura retal estavam dentro da normalidade para a espécie. Observaram-se placas cutâneas de circulares, policíclica e serpiginosa, recobertas por crostas melicéricas espessas e bem aderidas à lesão. As lesões freqüentemente apresentavam margem mais elevada em relação à região central, dolorosas ao toque e sem prurido, com distribuição generalizada, embora com maior envolvimento do tronco e da região cervical (Fig. 1 e 2).
A interpretação do hemograma revelou anemia (volume globular de 26\%), fibrinogênio de $400 \mathrm{mg} / \mathrm{dl}$, leucocitose $(19500 \mathrm{cels} / \mu \mathrm{l})$, neutrofilia $(17745 \mathrm{cels} / \mu \mathrm{l})$ e linfopenia $(1365 \mathrm{cels} / \mu \mathrm{l})$. Os perfis bioquímicos séricos hepático, renal e muscular estavam inalterados. A proteína sérica total foi $9,1 \mathrm{~g} / \mathrm{dl}$ com $1,52 \mathrm{~g} / \mathrm{dl}$ de albumina $\mathrm{e}$ $8,08 \mathrm{~g} / \mathrm{dl}$ de globulina. $\mathrm{O}$ fracionamento eletroforético revelou hipergamaglobulinemia.

Realizaram-se esfregaços sangüíneos para pesquisa de hemoparasitas, pesquisa de células Lupus eritematoso (LE) e imunodifusão em gel ágar para anemia infecciosa eqüina, obtendo-se resultados negativos. Nenhum achado significante foi obtido em cultivos bacterianos, contudo fungos das espécies Aspergillus sp., Fusarium sp. e Penicillium spp. foram isolados de raspados das lesões.

Biopsias da lesão foram submetidas ao exame histológico e coradas pelo ácido periódico de Schiff (PAS) e por hematoxilina e eosina (HE). Nenhuma estrutura fúngica foi identificada nas amostras coradas pelo PAS. Os achados histopatológicos demonstraram dermatite pustular acantolítica subcorneal. A epiderme apresentava-se discretamente acantótica com áreas de discreta a moderada hiperceratose ortoceratótica e áreas com pústula subcorneal, com acúmulo de neutrófilos e numerosos ceratinócitos acantolíticos. A base da pústula, na camada granulosa e espinhosa exibia ceratinócitos se desprendendo das células epidérmicas vicinais (Fig. 3 e 4). A derme superficial apresentava discreto infiltrado misto neutrofílico e macrofágico nas regiões perivascular e intersticial. Os anexos sudoríparos, sebáceos e foliculares não apresentaram alterações dignas de nota.

A terapia instituída foi enrofloxacina $(5 \mathrm{mg} / \mathrm{kg} / \mathrm{pv}$, uma vez ao dia) por sete dias e dexametasona $(0,1 \mathrm{mg} / \mathrm{kg} / \mathrm{pv}$, uma vez ao dia) por 14 dias. Com a melhora do quadro clínico, a dose de dexametasona foi seqüencialmente reduzida pela metade a cada duas semanas até atingir a dose de $0,0125 \mathrm{mg} / \mathrm{kg} / \mathrm{pv}$, uma vez ao dia (dose de manutenção). Nenhum efeito adverso à corticoterapia foi evidenciado e o animal recebeu alta 45 dias após o início do tratamento, com completa remissão dos sinais clínicos. A dose de manutenção foi mantida por mais 45 dias na propriedade. 


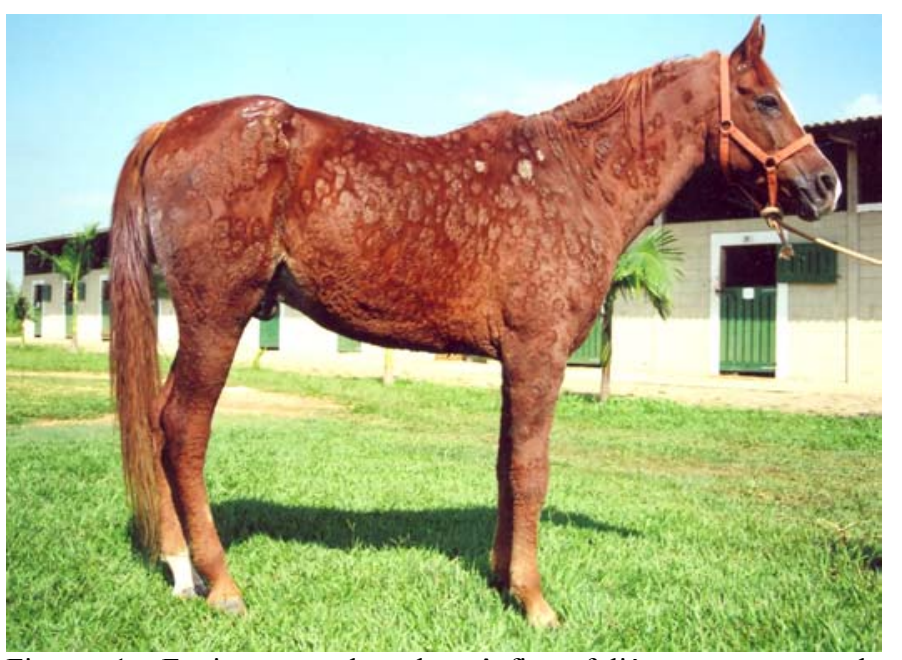

Figura 1. Eqüino portador de pênfigo foliáceo, apresentando dermatopatia generalizada.

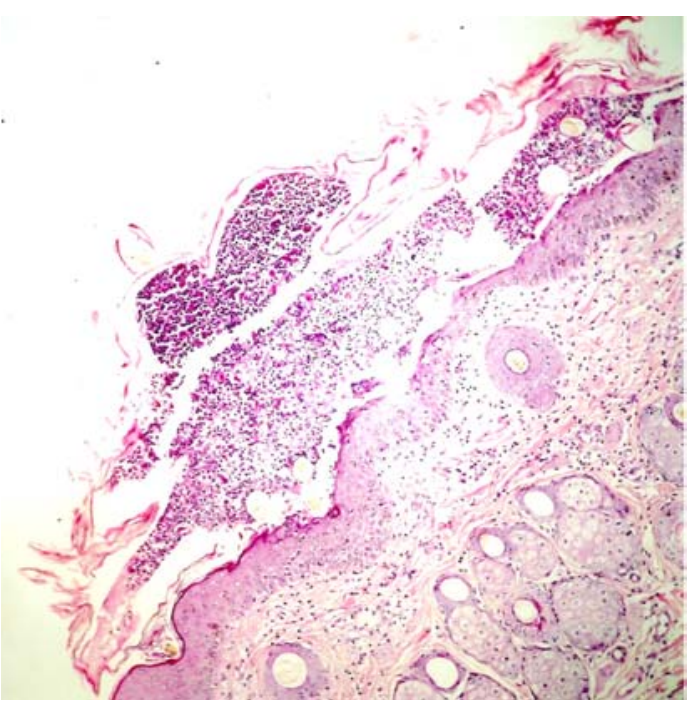

Figuras 3. Epiderme discretamente acantótica com trechos de discreta a moderada hiperceratose ortoceratótica, presença de pústula subcorneal com acúmulo de neutrófilos e numerosos ceratinócitos acantolíticos. HE.100x.

Após 70 dias do final do tratamento, o animal voltou a apresentar o mesmo quadro clínico sendo novamente encaminhado à clínica. Novos exames histológicos das lesões foram realizados e foi novamente diagnosticado PF. A corticoterapia com dexametasona foi reinstituída. Durante o tratamento o animal apresentou gastrite, confirmado por exame gastroscópico e foi instituído o tratamento com omeprazol $(4 \mathrm{mg} / \mathrm{kg} / \mathrm{pv}$, uma vez ao dia) por 28 dias. Após 52 dias de corticoterapia, o animal recebeu alta com total remissão das lesões cutâneas, foi

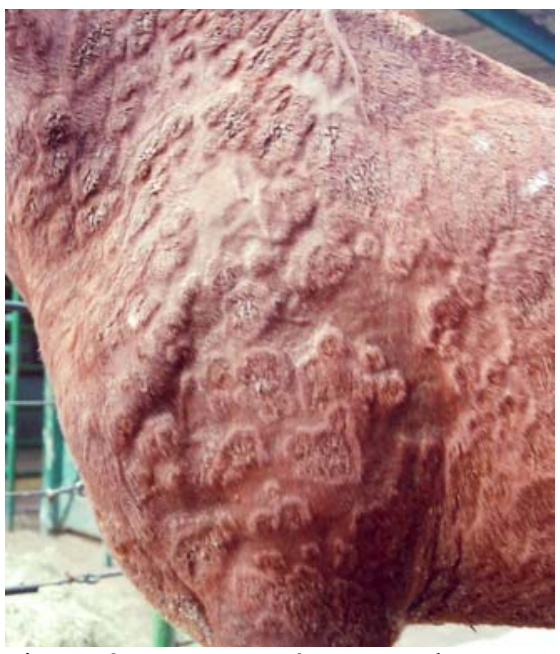

Figura 2. Lesões cutâneas recobertas por crostas espessas e aderidas.

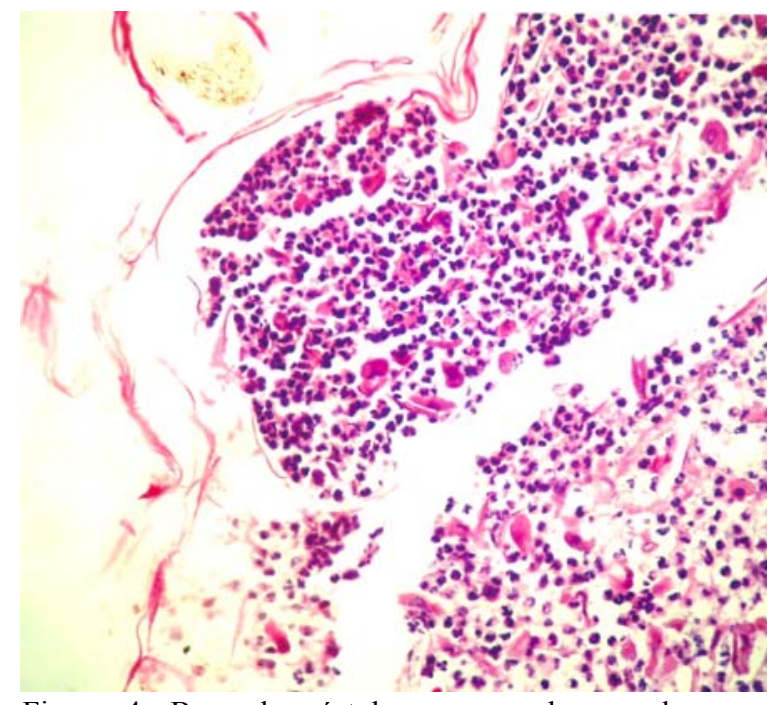

Figura 4. Base da pústula, na camada granulosa e espinhosa, com ceratinócitos se desprendendo da epiderme, derme superficial com discreto infiltrado perivascular a intersticial misto, neutrofílico e macrofágico. HE.400x.

recomendado o uso contínuo da dose de manutenção de dexametasona.

\section{DISCUSSÃO}

Pênfigo foliáceo é a doença auto-imune mais comum na espécie eqüina, contudo seu relato é pouco freqüente (Vandenabeele et al., 2004). Esse caso é o primeiro a ser relatado na literatura brasileira consultada. 
A enfermidade não tem predileção por sexo ou por faixa etária, podendo acometer animais desde poucos meses até 25 anos de idade (Laing et al., 1992; Vandenabeele et al., 2004; Zabel et al., 2005). Segundo Scott et al. (1987), a raça Appaloosa é a mais afetada, contudo Vandenabeele et al. (2004) em um estudo retrospectivo, não observaram predileção da doença por nenhuma raça. Em ambos os relatos, os animais da raça Árabe representavam, respectivamente, $20 \%(n=9)$ e $10 \%(n=20)$ dos casos estudados.

A exposição prévia a insetos como os Simuliidae, que desencadeia uma reação de hipersensibilidade e produção cruzada de anticorpos contra os ceratinócitos e o uso de antihelmínticos já foram relatados com o desenvolvimento da doença (Vandenabeele et al., 2004). A associação de sulfas com trimetoprim aumenta o risco da doença em seres humanos e cães e, possivelmente, também em cavalos (Brenner et al., 1998; Vandenabeele et al., 2004). Estresse e doenças sistêmicas concomitantes podem desencadear PF em eqüinos (Vandenabeele et al., 2004). Neste caso não foram usados antimicrobianos e nenhuma doença sistêmica foi relatada pelo proprietário, antes do aparecimento das manifestações clínicas.

A localização inicial e a velocidade com que as lesões se disseminaram neste eqüino são semelhantes às descritas por Scott e Miller (2003). As lesões erosadas e alopécicas, com presença de crostas, edema e descamação, descritas neste trabalho, são as principais lesões observadas em eqüinos acometidos pelo $\mathrm{PF}$ (Scott, 1987; Vandenabeele et al., 2004; Stahli et al., 2005). Edema na região ventral, depressão e perda de peso, observadas também neste caso, são encontrados em diversos relatos de $\mathrm{PF}$ em eqüinos (Peter et al., 1981; Stannard, 2000; Scott e Miller, 2003).

Assim como neste relato, Peter (1981), Emonnd e Frevert (1986), Laing et al. (1992), Vandenabeele et al. (2004) também observaram anemia, leucocitose com neutrofilia, hiperproteinemia e hiperglobulinemia. Nesse relato a hiperglobulinemia foi conseqüência da hipergamaglobulinemia, sugerindo o aumento de anticorpos. Scott (1987) também observou hipoalbuminemia, contudo, em sua descrição havia hiperfibrinogenia, diferente dos achados aqui citados. Talvez a reação inflamatória cutânea possa contribuir para explicar estas variações, já que no presente caso, havia pouca ou nenhuma infecção bacteriana importante.

Os gêneros de fungos isolados são semelhantes àqueles cultivados a partir de raspados de pele de cavalos sadios, sendo considerados saprófitos para a espécie e sem significado clínico (Ihrke et al., 1988; Scott e Miller, 2003). O cultivo bacteriano e o exame histológico descartaram, respectivamente, a possibilidade de dermatofilose e de dermatofitose, doenças cutâneas comuns em eqüinos, consideradas por vários autores, em outros países, como entidades a serem submetidas à diferenciação diagnóstica com o PF (Stannard, 2000; Scott e Miller, 2003; Vandenabeele et al., 2004).

Dermatite pustular acantolítica subcorneal, evidenciada pelo exame histológico da pele, foi semelhante aos achados clássicos, descritos em outros casos clínicos (Pfeiffer et al., 1988; Scott e Miller, 2003; Vandenabeele et al., 2004; Stahli et al., 2005).

O uso inicial de dexametasona $(0,1 \mathrm{mg} / \mathrm{kg} / \mathrm{pv}$, uma vez ao dia) no tratamento deste animal foi baseado nos relatos de diversos autores. Geralmente, a melhora clínica após o início do tratamento com dexametasona, ocorre em poucos dias. Contudo, o tempo de tratamento é muito variado e alguns cavalos necessitam de uso contínuo da dose de manutenção para evitar recidiva (Scott e Miller, 2003). Em geral, animais mais jovens respondem melhor à terapia e têm menos casos de recorrências, quando comparados aos animais mais velhos (Scott e Miller, 2003; Vandenabeele et al., 2004).

\section{REFERÊNCIAS BIBLIOGRÁFICAS}

BRENNER, S.; BIALY-GOLAN, A.; RUOCCO, V. Drug-induced pemphigus. Clin. Dermatol., v.16, p.393-397, 1998.

EMONND, R.J.; FREVERT, C. Pemphigus foliaceus in a horse. Mod. Vet. Pract., v.67, p.527-530, 1986.

IHRKE, P.J.; WONG, A.; STANNARD, A.A. et al. Cutaneous fungal flora in twenty horses free of skin or ocular disease. Am. J. Vet. Res., v.49, p.770-772, 1988 . 
JOHNSON, M.E.; SCOTT, D.W.; MANNING, T.O. A case of pemphigus foliaceus in the horse. Equine Pract., v. 3, p.40-45, 1981.

LAING, J.A.; ROTHWELL, T.L.W.; PENHALE, W.J. Pemphigus foliaceus in a 2-month-old foal. Equine Vet. J., v. 24, p.490-491, 1992.

MESSER, N.T.; KNIGHT, A.P. Pemphigus foliaceus in a horse. J. Am. Vet. Med. Assoc., v.180, p.938-940, 1982.

MULLOWNEY, P.C. Dermatologic disease of horses Part V. Allergic, immune-mediated, and miscellaneous skin diseases. Compend. Cont. Educ., v.7, p.217-228, 1985.

PAPPALARDO, E.; ABRAMO, F.; NOLI, C. Pemphigus foliaceus in a goat. Vet. Dermatol., v.13, p.331-326, 2002.

PETER, J.E.; MORRIS, P.G.; GORDON, B.J. Pemphigus in a thoroughbred. Vet. Med. Small Anim. Clin., v.76, p.1203-1206, 1981.

PFEIFFER, C.J.; SPURLOCK, S.; BALL, M. Ultrastructural aspects of equine pemphigus foliaceus-like dermatitis. Report of cases. $J$. Submicrosc. Citol. Pathol., v.20, p.453-461, 1988.

ROTHWELL, T.L.W.; MERRIT, G.C.; MIDDLETON, D.J. et al. Possible pemphigus foliaceus in a horse. Aust. Vet. J., v.62, p.429430, 1985.

SCOTT, D.W.; MILLER, W.H. Jr. Equine dermatology. St Louis: Saunders, 2003. 823p.
SCOTT, D.W.; WALTON, D.K.; SLATER, M.R. et al. Immune-Mediated dermatoses in domestic animals: ten years after - part 1. Compend. Cont. Educ., v.9, p.424-435, 1987.

SCOTT, D.W.; WALTON, D.K.; SMITH, C.A. et al. Pitfalls in immunofluorescence testing in dermatology. III. Pemphigus-like antibodies in the horse and direct immunoflurescence testing in equine dermatolophilosis. Cornell Vet., v.74, p.305-311, 1984.

STAHLI, P.; GREST, P.; FAVROT, C. et al. Pemphigus foliaceus in a Haflinger gelding. Schweiz. Arch. Tierheilkd., v.147, p.213-217, 2005.

STANNARD, A.A. Immunologic diseases. Vet. Dermatol., v.11, p.163-178, 2000.

VANDENABEELE, S.I.J.; WHITE, S.D.; AFFOLTER, V.K. et al. Pemphigus foliaceus in the horse: a retrospective study of 20 cases. Vet. Dermatol., v.15, p.381-388, 2004.

WILLIAMS, M.A.; DOWLING, P.M.; ANGARANO, D.W. et al. Paraneoplastic bullous stomatits in a horse. J. Am. Vet. Med. Assoc., v.207, p.331-334, 1995.

ZABEL, S.; MUELLER, R.S.; FIESELER, K.V. et al. Review of 15 cases of pemphigus foliaceus in horses and a survey of the literature. Vet. Rec., v.157, p.505-509, 2005. 